University of North Florida

UNIVERSITY of

NORTH FLORIDA.

UNF Digital Commons

6-15-1998

\title{
Reactions of Oxygen Atoms with Van der Waals Complexes: The Effect of Complex Formation on the Internal Energy Distribution in the Products
}

\author{
A B. McCoy \\ Michael W. Lufaso \\ University of North Florida, michael.lufaso@unf.edu \\ M Veneziani \\ S Atrill \\ R Naaman \\ Follow this and additional works at: https://digitalcommons.unf.edu/achm_facpub \\ Part of the Chemistry Commons
}

\footnotetext{
Recommended Citation Products" (1998). Chemistry Faculty Publications. 7.

https://digitalcommons.unf.edu/achm_facpub/7

This Article is brought to you for free and open access by the Department of Chemistry at UNF Digital Commons. It has been accepted for inclusion in Chemistry Faculty Publications by an authorized administrator of UNF Digital Commons. For more information, please contact Digital Projects.

(C) 6-15-1998 All Rights Reserved
}

McCoy, A B.; Lufaso, Michael W.; Veneziani, M; Atrill, S; and Naaman, R, "Reactions of Oxygen Atoms with Van der Waals Complexes: The Effect of Complex Formation on the Internal Energy Distribution in the

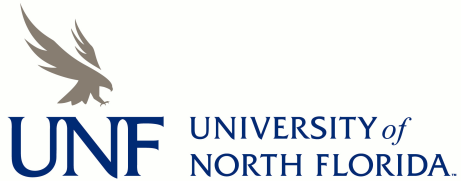




\title{
Reactions of oxygen atoms with van der Waals complexes: The effect of complex formation on the internal energy distribution in the products
}

\author{
A. B. McCoy and M. W. Lufaso \\ Department of Chemistry, The Ohio State University, Columbus, Ohio 43210 \\ M. Veneziani, S. Atrill, and R. Naaman \\ Department of Chemical Physics, Weizmann Institute of Science, Rehovot 76100, Israel
}

(Received 4 November 1997; accepted 13 March 1998)

\begin{abstract}
Reactions of atomic oxygen with complexes containing $\mathrm{HCl}$ are investigated and the $\mathrm{OH}$ product state distributions are compared to those observed for the corresponding reactions of $\mathrm{HCl}$ monomers. In previous studies of reactions of $\mathrm{O}\left({ }^{3} P\right)$ with $\mathrm{HCl}$ and hydrocarbon complexes, rotationally colder $\mathrm{OH}$ product state distributions were observed, when compared to the corresponding reactions of monomers. In contrast, we find that reactions of $\mathrm{O}\left({ }^{1} D\right)$ with $\mathrm{HCl}$ clusters yield $\mathrm{OH}$ rotational distributions that are unaffected by the incorporation of $\mathrm{HCl}$ into a van der Waals complex. Quasiclassical trajectories are run on collisions of oxygen with $\mathrm{HCl}$ and $\mathrm{Ar} \cdots \mathrm{HCl}$ at $1 \mathrm{eV}$ collision energies to investigate the differences in the dynamics of the $\mathrm{O}\left({ }^{1} D\right)$ and $\mathrm{O}\left({ }^{3} P\right)$ reactions. It is found that when the van der Waals complex is longer lived than the collision complex, rotational and vibrational cooling are observed. In contrast, when the dissociation of the van der Waals complex is prompt, compared to the collision complex lifetime, the effects of complex formation on the internal energy of the $\mathrm{OH}$ product become negligible. (C) 1998 American Institute of Physics. [S0021-9606(98)01623-7]
\end{abstract}

\section{INTRODUCTION}

Over the past 25 years, experimental and theoretical approaches have been developed to the point that a variety of atom plus diatom $(A+B C)$ reactions have been mapped out very accurately. ${ }^{1-3}$. While much can be learned from these studies, most chemistry occurs in solvated environments. Therefore, understanding how changes to the environment affect reaction dynamics and product state distributions has become an important question in chemical physics. One way to begin to understand these effects is through studies of reactions in which one or both of the reacting species are incorporated into a weakly bound cluster. A variety of reactions have been investigated in this manner, either by photoinitiating a reaction inside a cluster, ${ }^{4-11}$ or by studying the bimolecular reaction of a weakly bound complex with an atom or molecule directly., ${ }^{9,12-19}$

In the present study, we focus on reactions of atomic oxygen in its ground $\left({ }^{3} P\right)$ or first excited $\left({ }^{1} D\right)$ electronic state with complexes containing $\mathrm{HCl}$. Because of their importance in fundamental reaction dynamics ${ }^{20,21}$ and the significant role reactions of $\mathrm{O}\left({ }^{1} D\right)$ play in atmospheric chemistry, ${ }^{22}$ the reaction of atomic oxygen with $\mathrm{HCl}$ has been studied extensively both theoretically ${ }^{23,24}$ and experimentally. ${ }^{25,26}$ However, much less work has probed reactions of atomic oxygen with complexes of $\mathrm{HCl}^{17}$

The specific question that we will address is how the product state distributions resulting from reactions in clusters differ from those obtained from the corresponding reactions of isolated molecules. In many cases, it has been found that incorporating one or both of the reactants into a van der Waals complex leads to products that contain less internal energy compared to the products of the corresponding reac- tion of isolated atoms and molecules. This effect is particularly profound for the angular momentum distributions. The simpleminded explanation for the observed rotational cooling assumes that the "third body," namely the spectator to the reaction, shares angular momentum with the reacting species. As a result, less angular momentum is expressed in the reaction products. When the issue was studied in detail, ${ }^{27,28}$ it was found that in some cases the rotational cooling exceeds that predicted by a simple statistical model. This can be explained by assuming that during the very slow dissociation of the collision complex, there is efficient transfer of rotational energy to translational energy. ${ }^{29}$

The reaction of atomic oxygen with $\mathrm{HCl}$ provides a good laboratory in which we can investigate the mechanisms for the above processes. From our previous experimental studies of the reactions of $\left.\mathrm{O}^{3} \mathrm{P}\right)$ with $\mathrm{HCl},(\mathrm{HCl})_{2}$, and $\mathrm{Ar} \cdot \mathrm{HCl}$, we know that the addition of the complexing atom or molecule leads to longer lived reaction complexes than is observed for the reaction of isolated $\mathrm{HCl}$ molecules. ${ }^{17}$ This observation is consistent with observed colder angular momentum distributions for the $\mathrm{OH}$ products. By contrast, in the present work, we find that in the $\mathrm{O}\left({ }^{1} D\right)+\mathrm{HCl}$ reaction rotational cooling of the $\mathrm{OH}$ products cannot be observed experimentally when the $\mathrm{HCl}$ is complexed with $\mathrm{Ar}$ or other $\mathrm{HCl}$ molecules.

In order to understand the experimental findings described above, we use classical mechanics ${ }^{30,31}$ to simulate reactions of $\mathrm{O}\left({ }^{1} D\right)$ and $\left.\mathrm{O}^{3} P\right)$ with $\mathrm{HCl}$ and $\mathrm{Ar} \cdots \mathrm{HCl}$. We obtain identical rotational distributions for the $\mathrm{OH}$ products from the reactions of $\mathrm{O}\left({ }^{1} D\right)$ with $\mathrm{HCl}$ and $\mathrm{Ar} \cdots \mathrm{HCl}$, whereas there is measurable cooling in the $\mathrm{OH}$ products of the $\mathrm{O}\left({ }^{3} P\right)$ reaction. We explain the observed differences in 
the ability of the complexing atom or molecule to act as a "cooling element" for the $\mathrm{OH}$ products in terms of the lifetime of the van der Waals complex compared to that of the collision complex. In the case of the $\mathrm{O}\left({ }^{1} D\right)+\mathrm{HCl}$ reaction, the $\mathrm{HOCl}$ reaction complex is strongly bound and can exist for several picoseconds before dissociating into products whereas the dissociation of the $\mathrm{Ar} \cdots \mathrm{OHCl}$ complex is prompt. In contrast, for the $\mathrm{O}\left({ }^{3} \mathrm{P}\right)+\mathrm{HCl}$ reaction, the $\mathrm{OHCl}$ transition state complex lives for no more than one or two vibrational periods of the $\mathrm{HCl}$ stretch whereas the $\mathrm{Ar} \cdots \mathrm{OH}$ complex survives for several hundred femtoseconds.

The remainder of the paper is organized as follows. In Sec. II the experimental methods and theoretical approaches are discussed. Results are presented and discussed in Sec. III and the results are summarized in Sec. IV.

\section{METHODS}

\section{A. Experiment}

The experimental setup for the investigation of the reactions of $\mathrm{O}\left({ }^{1} D\right)$ with $\mathrm{HCl}$ clusters has been described previously. ${ }^{29}$ Therefore, the details will not be repeated here. For the present study, a crossed molecular beam setup is used in which a beam of $\mathrm{HCl}$ collides with fast $\mathrm{O}\left({ }^{1} D\right)$ atoms, produced by photodissociation of $\mathrm{N}_{2} \mathrm{O}$ at $193 \mathrm{~nm}$ in the region where the two beams intersect. The photodissociation laser is a ArF excimer laser (Lambda Physik, Compex 102). A frequency doubled Nd:Yag pumped dye laser (SpectraPhysics) is used to create the tunable UV light for the laserinduced fluorescence (LIF) measurements of the $\mathrm{OH}$ product.

\section{B. Theory}

In order to understand the experimental $\mathrm{OH}$ product state distributions, we have run several ensembles of classical trajectories. We focus on four separate systems that model reactions of ground state atomic oxygen $\left[O\left({ }^{3} P\right)\right]$ and oxygen in its first excited electronic state $\left[\mathrm{O}\left({ }^{1} D\right)\right]$ with $\mathrm{HCl}$ and $\mathrm{Ar} \cdots \mathrm{HCl}$ complexes. For this comparison, all four sets of trajectories are run at $1 \mathrm{eV}$ collision energies with zero-point energy in all degrees of freedom.

\section{Initial conditions and propagations}

The initial conditions of the trajectories are sampled from a long time propagation of intermolecular dynamics of $\mathrm{Ar} \cdots \mathrm{HCl}$ with zero-point energy in both of the intermolecular modes, the $\mathrm{HCl}$ in its minimum energy configuration and total angular momentum $J=0$. The dynamics is initiated with the oxygen atom at least $10.6 \AA$ from the center of mass of $\mathrm{HCl}$ or $\mathrm{Ar} \cdots \mathrm{HCl}$. The relative kinetic energy of the collision partners is $1 \mathrm{eV}$. Impact parameters and the orientation of reactants are chosen randomly using a Monte Carlo sampling procedure. ${ }^{31}$ For $\mathrm{O}\left({ }^{1} D\right)+\mathrm{HCl}$ collisions, $b_{\max }$ $=7.94 \AA$, while $b_{\max }=3.97 \AA$ for the $\mathrm{O}\left({ }^{3} P\right)+\mathrm{HCl}$ collisions. Finally, to facilitate comparison of the reactivity of $\mathrm{HCl}$ and $\mathrm{Ar} \cdot \mathrm{HCl}$, the same initial conditions are used for both sets of propagations.

The trajectories are propagated using a Gear algorithm and all trajectories are run until the distances between the product species are larger than $8 \AA$ or the trajectory has been run for longer than $1.2 \mathrm{ps}$ for collisions with $\mathrm{HCl}$ reactions and $2.4 \mathrm{ps}$ for collisions with $\mathrm{Ar} \cdots \mathrm{HCl}$. For all reactions except the $\mathrm{O}\left({ }^{3} P\right)+\mathrm{Ar} \cdots \mathrm{HCl}$ reaction, 10000 trajectories are run. In the case of the $\mathrm{O}\left({ }^{3} \mathrm{P}\right)+\mathrm{Ar} \cdots \mathrm{HCl}$ reaction 20000 trajectories are required to obtain meaningful statistics.

\section{Potential energy surfaces}

For the present study, we approximate the intermolecular $\mathrm{O}+\mathrm{Ar} \cdots \mathrm{HCl}$ potential as a sum of pairwise interactions. Many of the contributing interactions have been characterized by fitting a combination of scattering data, the observed spectra, and $a b$ initio points to simple functional forms. ${ }^{32-36}$ The most important ingredient in the global surface is the underlying $\mathrm{O}+\mathrm{HCl}$ potential. In the present study, we use the $\mathrm{O}\left({ }^{1} D\right)+\mathrm{HCl}$ potential of $\mathrm{Schink}^{33}$ and the $\mathrm{O}\left({ }^{3} P\right)+\mathrm{HCl}$ potential of Koizumi et al. ${ }^{32}$ Both of these potentials were fit to $a b$ initio as well as scattering data and have been used in a variety of classical and quantum mechanical studies of the $\mathrm{O}+\mathrm{HCl}$ reaction. ${ }^{20,21}$

The interactions with the argon atom are more difficult to construct. In the reactant channel, the argon atom sees an oxygen atom, either $\mathrm{O}\left({ }^{3} P\right)$ or $\mathrm{O}\left({ }^{1} D\right)$, and an $\mathrm{HCl}$ molecule. In the product channels, the argon atom is in the presence of either $\mathrm{Cl}+\mathrm{OH}$ or $\mathrm{H}+\mathrm{OCl}$. While potential surfaces that describe most of the necessary intermolecular potentials have been characterized, ${ }^{34-38}$ the interaction potentials between an argon atom and the reaction intermediates have not. In the absence of this information, we model the intermolecular potential as the sum of atom-atom interactions. The advantage of this approach, which has been previously employed in studies of reactions of van der Waals dimers, ${ }^{10,18,19}$ is that the resulting potentials are necessarily smooth everywhere.

In the present study, the $\mathrm{Ar}^{\cdots} \mathrm{Cl}$ and $\mathrm{Ar} \cdots \mathrm{O}\left({ }^{1} D\right)$ potentials are modeled by a Lennard-Jones $(12,6)$ function,

$$
V(r)=4 \epsilon\left[\left(\frac{\sigma}{r}\right)^{12}-\left(\frac{\sigma}{r}\right)^{6}\right],
$$

with $\epsilon=0.01442 \mathrm{eV}$ and $\sigma=3.47 \AA .{ }^{37}$ The Ar $\cdots H$ interaction is given by the Slater-Buckingham $\exp (\alpha, 6)$ function,

$$
V(r)=\frac{\epsilon}{1-6 / \alpha}\left[\frac{6}{\alpha} e^{\alpha\left(1-r_{m} / r\right)}-\left(\frac{r_{m}}{r}\right)^{6}\right],
$$

where $\alpha=14.23, \epsilon=38.717 \mathrm{~cm}^{-1}$, and $r_{m}=2.85 \AA .^{38} \mathrm{Fi}-$ nally, the $\operatorname{Ar} \cdots \mathrm{O}\left({ }^{3} P\right)$ is given by a Morse function,

$$
V(r)=D_{e}\left[1-e^{-\beta\left(r-r_{e}\right)}\right]^{2},
$$

with $\quad D_{e}=0.0104015 \mathrm{eV}, \quad r_{e}=3.45 \AA, \quad$ and $\quad \beta$ $=1.748 \AA^{-1} .^{35}$

While the above pairwise additive potentials will not describe the $\mathrm{Ar} \cdots \mathrm{HCl}$ or the $\mathrm{Ar} \cdots \mathrm{OH}$ intermolecular potentials with spectroscopic accuracy, they provide good descriptions of these complexes. When $\mathrm{HCl}$ is in its equilibrium geometry, the dissociation energy of $\mathrm{Ar} \cdots \mathrm{HCl}$ is $150 \mathrm{~cm}^{-1}$, which is in good agreement with the $175 \mathrm{~cm}^{-1}$ value computed from Hutson's H6(3) potential. ${ }^{34} \mathrm{~A}$ second minimum on the $\mathrm{Ar} \cdots \mathrm{HCl}$ surface is found for the $\mathrm{Ar}-\mathrm{Cl}-\mathrm{H}$ geometry. In this geometry, the system is predicted to be bound by $140 \mathrm{~cm}^{-1}$, 

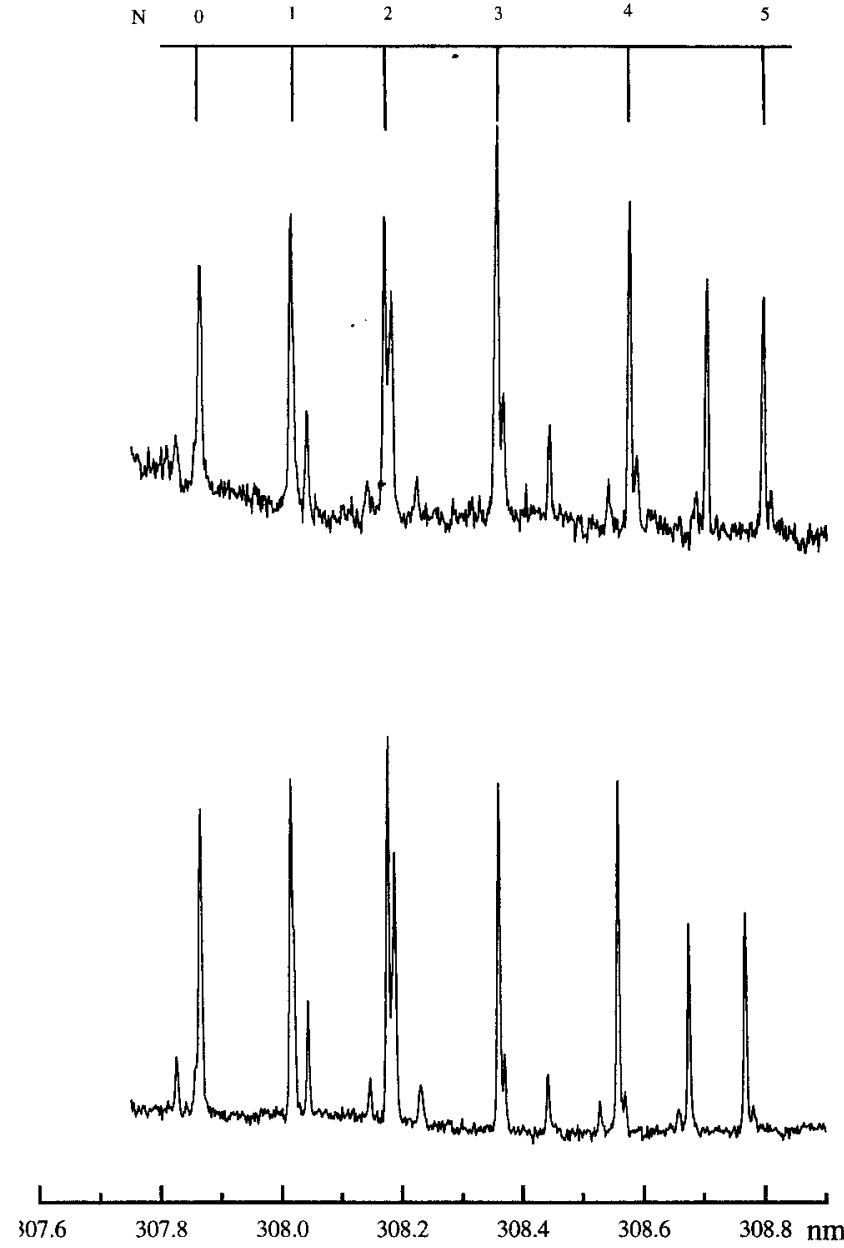

FIG. 1. The laser-induced fluorescence spectrum of the nascent $\mathrm{OH}$ products formed from the reaction of $O\left({ }^{1} D\right)$ with a beam of $\mathrm{HCl}$. The $Q_{1}$ branch of the $A-X$ transition is shown. In the upper panel the $\mathrm{HCl}$ pressure behind the nozzle was $1000 \mathrm{mbar}$ and the lower panel was obtained at a pressure of 300 mbar.

according to the spectroscopic potential, ${ }^{34}$ while the pairwise additive potential yields a value of $120 \mathrm{~cm}^{-1}$. The variation in the minimum $\mathrm{Ar}-\mathrm{Cl}$ distance as a function of the $\mathrm{Ar} \cdot \mathrm{HCl}$ angle is larger in our pairwise approximation to the intermolecular potential than in the spectroscopic surface, but in both cases, the average value is approximately $4 \AA$. The $\mathrm{Ar} \cdots \mathrm{OH}$ surface is also well represented by the pairwise additive approximation. For example, the sum of the $\mathrm{Ar} \cdots \mathrm{O}\left({ }^{3} P\right)$ and $\mathrm{Ar} \cdots \mathrm{H}$ surfaces has a minimum at the $\mathrm{Ar}-$ $\mathrm{H}-\mathrm{O}$ geometry with $D_{e}=108 \mathrm{~cm}^{-1}$, and $R_{e}=3.6 \AA$. These values are in good agreement with the reported $a b$ initio $\mathrm{Ar}-\mathrm{OH}\left(X^{2 \Sigma^{+}}\right)$surface: $100 \mathrm{~cm}^{-1}$ and $3.8 \AA^{39}$

\section{RESULTS}

\section{A. Experiment}

The $\mathrm{OH}$ rotational distributions, resulting from the reaction of $\mathrm{O}\left({ }^{1} D\right)$ with $\mathrm{HCl}$, have been investigated as a function of the $\mathrm{HCl}$ pressure behind the nozzle for $v_{\mathrm{OH}}=0,1$. Part of the resulting LIF spectrum, taken at two different $\mathrm{HCl}$ pressures, is shown in Fig. 1. The spectrum was obtained by monitoring the $A-X Q_{1}$ transition of $\mathrm{OH}(v=0)$, generated by the reaction of $\mathrm{O}\left({ }^{1} D\right)$ with a molecular beam of $\mathrm{HCl}$. The
TABLE I. Outcomes of the $\mathrm{O}\left({ }^{3} P\right)+\mathrm{HCl}$ and $\mathrm{Ar} \cdots \mathrm{HCl}$ collisions.

\begin{tabular}{lrcc}
\hline \multicolumn{1}{c}{ Products } & \multicolumn{1}{c}{$N_{t}$} & $\sigma / \AA^{2 a}$ & $b_{\max } / \AA$ \\
\hline $\mathrm{Cl}+\mathrm{OH}^{\mathrm{b}}$ & 62 & $0.14(0.02)$ & 1.50 \\
$\mathrm{O}+\mathrm{Ar}+\mathrm{HCl}^{\mathrm{c}}$ & 7969 & $15.8(0.2)$ & 3.93 \\
$\mathrm{Cl}+\mathrm{Ar}+\mathrm{OH}$ & 68 & $0.11(0.01)$ & 3.13 \\
\hline \hline
\end{tabular}

${ }^{a}$ The reported uncertainties, in Parentheses, represent one standard deviation from the reported cross sections.

${ }^{b} B$ ased on 10000 trajectories run at $1.0 \mathrm{eV}$ collision energies with $b_{\max }$ $=3.97 \AA$.

${ }^{c}$ Based on 20000 trajectories run at $1.0 \mathrm{eV}$ collision energies with $b_{\max }$ $=3.97 \AA$.

spectrum in the lower panel of Fig. 1 was obtained when the pressure behind the nozzle was 300 mbar of neat $\mathrm{HCl}$, while the spectrum in the upper panel was obtained at 1000 mbar. The rotational population obtained for the two $\mathrm{HCl}$ pressures show no noticeable differences. Further, the distributions remain basically identical when the pressure is varied from approximately 100 to 2000 mbar. Under the same conditions dramatic changes in the $\mathrm{OH}$ rotational distributions have been reported for reactions of $\mathrm{O}\left({ }^{3} P\right)$ and $\mathrm{HCl}^{17}$ and $\mathrm{O}\left({ }^{1} D\right)$ and $\mathrm{CH}_{4}{ }^{40}$

We conclude that for the reaction of $\mathrm{O}\left({ }^{1} D\right)$ with $\mathrm{HCl}$ complexes, the rotational energy distribution is not sensitive to cluster formation. To understand the origin of this apparent insensitivity, we look at the results of the classical trajectory studies of the $\mathrm{O}\left({ }^{3} P\right)+\mathrm{HCl}$ and $\mathrm{O}\left({ }^{1} D\right)+\mathrm{HCl}$ reactions.

\section{B. Reactions of $\mathrm{O}\left({ }^{3} \mathrm{P}\right)$ and $\mathrm{HCl}$ and $\mathrm{Ar} \cdots \mathrm{HCl}$}

There is one energetically accessible product channel for an $\mathrm{O}\left({ }^{3} \mathrm{P}\right)+\mathrm{HCl}$ collision at $1 \mathrm{eV}$ : formation of $\mathrm{OH}+\mathrm{Cl}$ and dissociation to the starting materials. As shown in Table I, given our choice of initial conditions only $0.6 \%$ of the trajectories form $\mathrm{OH}$.

When an argon atom is introduced, additional product channels become accessible. The observed outcomes are listed in Table I. Although the argon atom could form a complex with the $\mathrm{OH}$ products, the $\mathrm{Ar} \cdots \mathrm{OH}$ interaction potential is sufficiently weak, $D_{e} \approx 2.5 \%$ of the available energy, such that these complexes are extremely rare. The $\mathrm{Ar} \cdots \mathrm{HCl}$ binding energy is also two orders of magnitude smaller than the collision energy, explaining why the $\mathrm{Ar} \cdot \mathrm{HCl}$ complex dissociates in approximately $40 \%$ of the trajectories.

As the results in Table I show, the cross sections, $\sigma$, decrease by $30 \%$ when the argon atom is introduced while $b_{\text {max }}$ for the reactive process increases by $1.6 \AA$. The primary source of the increase in $b_{\max }$ for the collision of $\mathrm{O}\left({ }^{3} P\right)$ and $\mathrm{Ar} \cdots \mathrm{HCl}$ comes from the definition of this quantity. We have defined $b$ to be the impact parameter measured between the centers of mass of the colliding species, either $\mathrm{HCl}$ or $\mathrm{Ar} \cdots \mathrm{HCl}$. If instead we compare $b_{\max }$, measured from the center of mass of $\mathrm{HCl}$ we obtain $b_{\max }^{\mathrm{O}+\mathrm{HCl}}=1.5 \AA$ and $b_{\max }^{\mathrm{O}+\mathrm{Ar} \cdots \mathrm{HCl}}=1.77 \AA$.

The observed decrease in reaction cross section, $\sigma$, for the 

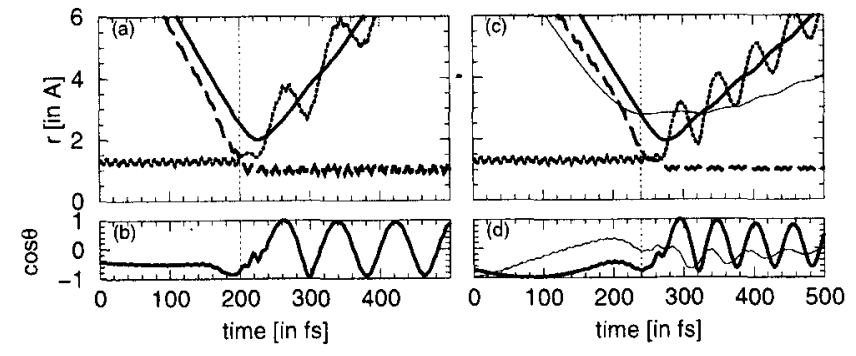

FIG. 2. Representative trajectory for $\mathrm{O}\left({ }^{3} P\right)+\mathrm{HCl}[(\mathrm{a})$ and (b) $]$ and $\mathrm{Ar} \cdots \mathrm{HCl}[(\mathrm{c})$ and (d) ] collisions that results in the formation of $\mathrm{OH}+\mathrm{Cl}$. In (a) and (c) the $\mathrm{OH}$ (dashed line), $\mathrm{OCl}$ (solid line), and $\mathrm{HCl}$ (dotted line) distances are plotted as a function of time. In (b) and (d) $\cos \left(\theta_{\mathrm{OHCl}}\right)$ is plotted. The thin lines in (c) and (d) provide the ArO distance and $\cos \theta_{\mathrm{ArHCl}}$, respectively. Finally, the vertical dotted line is provided to show when the collision complex is initially formed.

$$
\mathrm{O}\left({ }^{3} \mathrm{P}\right)+\mathrm{HCl} \rightarrow \mathrm{OH}+\mathrm{Cl}
$$

reaction also can be easily understood. It reflects the fact that even when we average over the zero-point vibrations of the $\mathrm{Ar} \cdots \mathrm{HCl}$ complex, our initial configurations are dominated by near collinear $\mathrm{Cl}-\mathrm{H}-\mathrm{Ar}$ geometries, as this represents the minimum energy geometry of $\mathrm{Ar} \cdot \mathrm{HCl}^{34}$ Because the $\mathrm{O}+\mathrm{HCl}$ reactive collisions occur with a near linear $\mathrm{O}-\mathrm{H}-\mathrm{Cl}$ transition state geometry, ${ }^{32}$ the argon atom in $\mathrm{Ar} \cdots \mathrm{HCl}$ effectively blocks the formation of the transition state complexes.

To clarify this point, a pair of representative trajectories are plotted in Fig. 2. Here, the panels on the left-hand side show a trajectory that represents an $\mathrm{O}+\mathrm{HCl}$ collision while the ones on the right give an $\mathrm{O}+\mathrm{Ar} \cdots \mathrm{HCl}$ trajectory. In the top panels, the distances between the hydrogen, oxygen, and chlorine atoms are plotted with thick lines. In both cases the oxygen and chlorine atoms undergo an impulsive collision, forming an $\mathrm{O}-\mathrm{H}-\mathrm{Cl}$ transition state complex that lives for approximately two vibrational periods of the $\mathrm{HCl}$ stretch before dissociating into the $\mathrm{Cl}+\mathrm{OH}$ products. In the lower panels, the thick line provides $\cos \theta_{\mathrm{OHCl}}$. We find that this value is approximately -1 when the complex is formed, indicating a near linear $\mathrm{O}-\mathrm{H}-\mathrm{Cl}$ transition state geometry. The thin lines in Figs. 2(c) and 2(d) provide information about the location of the argon atom during this $\mathrm{O}+\mathrm{Ar} \cdots \mathrm{HCl}$ collision. Focusing on Fig. 2(d), in which the thin line gives $\cos \theta_{\mathrm{ArHCl}}$, we find that initially the complex is in a near linear $\mathrm{Ar}-\mathrm{H}-\mathrm{Cl}$ geometry. As the oxygen atom approaches the $\mathrm{Ar} \cdots \mathrm{HCl}$ complex, $\theta_{\mathrm{ArHCl}}$ approaches $90^{\circ}$, enabling the formation of the $\mathrm{OHCl}$ complex. Finally, the thin line in Fig. 2(b) shows that as the complex dissociates, the $\mathrm{Cl}-\mathrm{O}$ distance increases faster than the Ar-O distance.

The above differences between the lifetimes of the $\mathrm{OHCl}$ collision complex and the Ar $\cdots \mathrm{OH}$ van der Waals complex are found to represent a general trend for the reactive collisions. This can be seen by comparing the lifetime distributions of the $\mathrm{OHCl}$ collision complex formed in $\mathrm{O}+\mathrm{HCl}$ and $\mathrm{O}+\mathrm{Ar} \cdots \mathrm{HCl}$ collisions to the distribution of $\mathrm{Ar} \cdots \mathrm{OH}$ lifetimes, plotted in Fig. 3. The shift in the distribution in Fig. 3 (b) relative to that in Fig. 3(a) is a result of the difference between the relative velocity of $\mathrm{O}\left({ }^{3} P\right)+\mathrm{HCl}$, compared to that for $\mathrm{O}\left({ }^{3} P\right)+\mathrm{Ar} \cdots \mathrm{HCl}$ at the same collision energy.

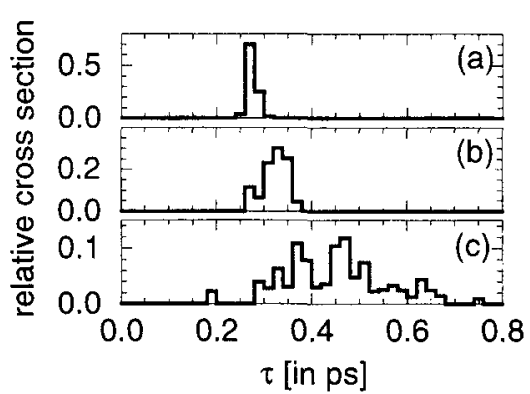

FIG. 3. Lifetime distributions for (a) the time when $r_{\mathrm{OCl}}$ exceeds $2.7 \AA$ for $\mathrm{O}+\mathrm{HCl}$ reactive collisions, (b) the time when $r_{\mathrm{OCl}}$ exceeds $2.7 \AA$ for $\mathrm{O}+\mathrm{Ar} \cdots \mathrm{HCl}$ reactive collisions, and (c), the time when $r_{\mathrm{ArH}}$ exceeds $5.3 \AA$ for $\mathrm{O}+\mathrm{Ar} \cdots \mathrm{HCl}$ reactive collisions.

Based on the masses of the two systems, the difference in the time of the collision, resulting from the change in the relative velocities, is expected to be approximately $0.15 \mathrm{ps}$, and this is what is seen. In addition, in Fig. 3(b), some of the collision energy is converted into kinetic energy of the departing argon atom. This second effect explains the broadening of the $\mathrm{OCl}$ lifetime distribution in Fig. 3(b) compared to that in Fig. 3(a). Finally, comparison of Figs. 3(b) and 3(c) shows that the argon atom remains in a complex with the $\mathrm{OH}$ product for as much as $0.5 \mathrm{ps}$ after the $\mathrm{OHCl}$ complex has dissociated.

One consequence of the existence of short-lived $\mathrm{Ar} \cdots \mathrm{OH}$ van der Waals complexes comes in lowering the internal energy of the $\mathrm{OH}$ product, plotted in Fig. 4. Here the distributions for the $\mathrm{OH}$ formed from $\mathrm{O}+\mathrm{HCl}$ collisions are plotted with thin lines and those distributions obtained from $\mathrm{O}+\mathrm{Ar} \cdots \mathrm{HCl}$ collisions are plotted with broad lines. Comparing the distributions, we find that the rotational and vibrational distributions are shifted to lower energies. These trends are consistent with the short-lived $\mathrm{Ar} \cdots \mathrm{OH}$ interme-

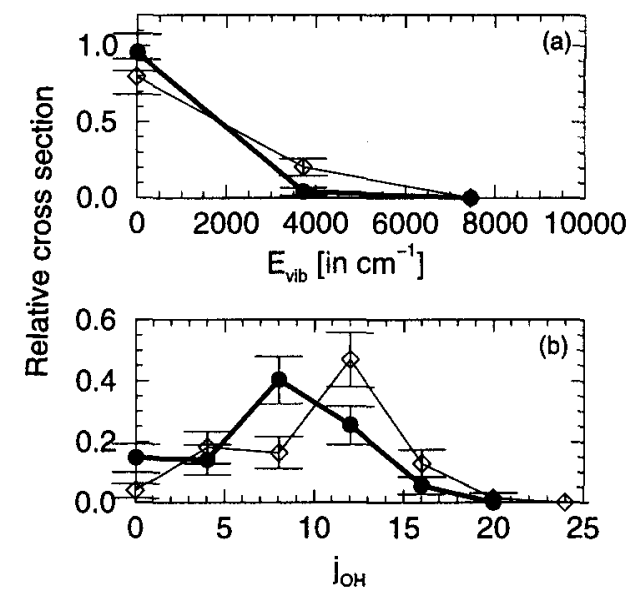

FIG. 4. Internal energy distributions for $\mathrm{OH}$ formed from reactions of $\mathrm{O}\left({ }^{3} P\right)$ with $\mathrm{HCl}$ (thin line) and $\mathrm{Ar}-\mathrm{HCl}$ (broad line). In (a), the vibrational energy distributions of the $\mathrm{OH}$ products are plotted. Each point represents results that have vibrational energies between $E_{\mathrm{vib}}-\omega_{\mathrm{OH}} / 2 \mathrm{~cm}^{-1}$ and $E_{\mathrm{vib}}+\omega_{\mathrm{OH}} / 2 \mathrm{~cm}^{-1}$. The uncertainties represent one standard deviation. The angular momentum distributions are plotted in (b). Here each point represents all trajectories that have $\mathrm{OH}$ angular momentum between $j_{\mathrm{OH}}-2$ and $j_{\mathrm{OH}}+2$. All plots are normalized so that the sum of the relative cross sections is unity. 
TABLE II. Outcomes of the $\mathrm{O}\left({ }^{1} D\right)+\mathrm{HCl}$ collisions. Results are based on 10000 trajectories run at $1.0 \mathrm{eV}$ collision energies with $b_{\max }=7.94 \AA$.

\begin{tabular}{lrll}
\hline Products & $N_{t}$ & \multicolumn{1}{c}{$\sigma / \AA^{2 \mathrm{a}}$} & $b_{\max } / \AA$ \\
\hline $\mathrm{Cl}+\mathrm{OH}$ & 914 & $9.5(0.3)$ & 2.95 \\
$\mathrm{H}+\mathrm{OCl}$ & 31 & $0.32(0.06)$ & 1.65 \\
$\mathrm{HOCl}$ & 29 & $0.34(0.06)$ & 2.54 \\
\hline \hline
\end{tabular}

${ }^{a}$ The reported uncertainties, in parentheses, represent one standard deviation from the reported cross sections.

${ }^{b}$ The atoms remain in an $\mathrm{HOCl}$ complex when the trajectory is terminated after 1.2 ps.

diate where the argon atom acts as an effective cooling element. Similar results have been reported for classical studies of $\mathrm{O}\left({ }^{3} P\right)+$ hydrocarbon reactions. ${ }^{19}$

\section{Reactions of $\mathrm{O}\left({ }^{1} \mathrm{D}\right)$ and $\mathrm{HCl}$ and $\mathrm{Ar} \cdots \mathrm{HCl}$}

The above results should be contrasted with those for the $\mathrm{O}\left({ }^{1} D\right)+\mathrm{HCl}$ reaction. Again the reaction is studied for collision energies of $1 \mathrm{eV}$. At this total energy, there are four possible outcomes of an $\mathrm{O}\left({ }^{1} D\right)+\mathrm{HCl}$ inelastic collision. As before, $\mathrm{OH}+\mathrm{Cl}$ can be formed or the oxygen atom can give up energy to the $\mathrm{HCl}$ molecule. Because there is an additional $2.28 \mathrm{eV}$ of energy in this system compared to the $\mathrm{O}\left({ }^{3} P\right)+\mathrm{HCl}$ reaction, the $\mathrm{OCl}+\mathrm{H}$ product channel is opened. This channel is approximately $2.3 \mathrm{eV}$ higher in energy than the $\mathrm{O}\left({ }^{3} \mathrm{P}\right)+\mathrm{HCl}$ and $\mathrm{OH}+\mathrm{Cl}$ channels. Finally, a long-lived, metastable $\mathrm{HOCl}$ molecule may be formed. When an argon atom is introduced, all of the above channels remain energetically accessible. In addition, the Ar atom may form a complex with either one of the product species. The cross sections for all observed processes are reported in Tables II and III.

In contrast to the results for the $\mathrm{O}\left({ }^{3} P\right)$ system, here the introduction of the argon atom increases the cross sections. Further, in contrast to the $\mathrm{O}\left({ }^{3} P\right)$ reaction which proceeds through a linear $\mathrm{O}-\mathrm{H}-\mathrm{Cl}$ transition state geometry, in the $\mathrm{O}\left({ }^{1} D\right)+\mathrm{HCl}$ reaction, the oxygen atom inserts into the $\mathrm{HCl}$ bond, forming a strongly bound $\mathrm{HOCl}$ molecular intermediate. Therefore, the introduction of an Ar atom in a near linear $\mathrm{Ar}-\mathrm{H}-\mathrm{Cl}$ complex geometry will have little effect on the dynamics of this process. This can be seen in the representative $\mathrm{O}\left({ }^{1} D\right)+\mathrm{HCl}$ trajectories plotted in Fig. 5. In Figs. 5(a)

TABLE III. Outcomes of the $\mathrm{O}\left({ }^{1} D\right)+\mathrm{Ar} \cdots \mathrm{HCl}$ collisions. Results are based on 10000 trajectories run at $1.0 \mathrm{eV}$ collision energies with $b_{\max }$ $=7.94 \AA$.

\begin{tabular}{crcc}
\hline Products & $N_{t}$ & \multicolumn{1}{c}{$\sigma / \AA^{2 \mathrm{a}}$} & $b_{\max } / \AA$ \\
\hline $\mathrm{O}+\mathrm{Ar}+\mathrm{HCl}$ & 3020 & $37.3(0.7)$ & 7.76 \\
$\mathrm{Cl}+\mathrm{Ar} \cdots \mathrm{OH}$ & 2 & $0.02(0.01)$ & 2.02 \\
$\mathrm{Cl}+\mathrm{Ar}+\mathrm{OH}$ & 890 & $9.8(0.3)$ & 4.90 \\
$\mathrm{Ar} \cdot \mathrm{Cl}+\mathrm{OH}$ & 11 & $0.12(0.04)$ & 3.67 \\
$\mathrm{H}+\mathrm{Ar}+\mathrm{OCl}$ & 59 & $0.60(0.08)$ & 3.79 \\
$\mathrm{Ar}+\mathrm{HOCl}^{b}$ & 36 & $0.38(0.06)$ & 4.03 \\
\hline
\end{tabular}

${ }^{\mathrm{a} T h e}$ reported uncertainties, in parentheses, represent one standard deviation from the reported cross sections.

${ }^{\text {b }}$ The atoms remain in an $\mathrm{HOCl}$ complex when the trajectory is terminated after 2.4 ps.

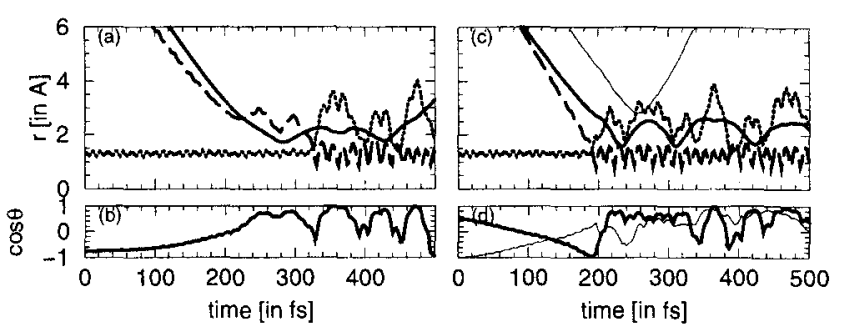

FIG. 5. Same as Fig. 2 for a typical $\mathrm{O}\left({ }^{1} D\right)+\mathrm{HCl}$ and $\mathrm{Ar} \cdots \mathrm{HCl}$ collisions.

and 5(c), we find that when the collision complex is formed, the $\mathrm{OHCl}$ angle flips from $180^{\circ}$ to $0^{\circ}$ indicating that the oxygen atom is now between the hydrogen and chlorine atoms. Further examination of the argon atom dynamics in Figs. 5(c) and 5(d) shows that it begins to separate from the $\mathrm{HOCl}$ complex approximately $50 \mathrm{fs}$ after this complex is formed and long before the complex falls apart. Not only does the argon atom leave the collision complex shortly after formation, but, comparing Figs. 2(c) and 5(c), we find that the argon atom leaves the reaction complex formed from the $\mathrm{O}\left({ }^{1} D\right)+\mathrm{HCl}$ collision with more kinetic energy.

While the above observations are based on individual trajectories, they translate into several general results, as can be seen in the average lifetime distributions, plotted in Fig. 6 . Comparing Figs. 6(a) and 6(b), we find that the trajectories for $\mathrm{O}\left({ }^{1} D\right)+\mathrm{Ar} \cdots \mathrm{HCl}$ lead to longer-lived complexes than when the Ar atom is not present. Further, by comparing Figs. 6(b) and 6(c), we find that for many of the trajectories the $\mathrm{Ar} \cdot \mathrm{HOCl}$ complex dissociates before the $\mathrm{HOCl}$ complex falls apart.

An important consequence of these relative lifetimes comes in the resulting internal energy distributions of the $\mathrm{OH}$ products, plotted in Fig. 7. In this case, the angular momentum distribution is unaffected by the presence of the argon atom. The vibrational energy distribution is shifted to lower energies. This trend can be rationalized by the fact that the argon atom removes internal energy from the $\mathrm{HOCl}$ complex, leading to the observed shift in the vibrational energy distributions. The prompt dissociation of the van der Waals complex results in the observation that there is no difference

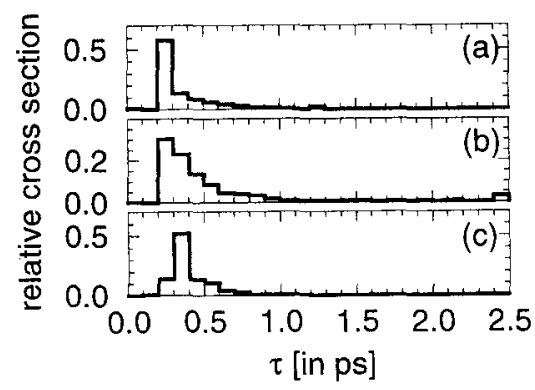

FIG. 6. Internal energy distributions for $\mathrm{OH}$ formed from a reactions of $\mathrm{O}\left({ }^{\prime} D\right)$ with $\mathrm{HCl}$ (thin line) and $\mathrm{Ar}-\mathrm{HCl}$ (broad line). In (a), the vibrational energy distributions of the $\mathrm{OH}$ products are plotted. Each point represents results that have vibrational energies between $E_{\mathrm{vib}}-\omega_{\mathrm{OH}} / 2 \mathrm{~cm}^{-1}$ and $E_{\text {vib }}+\omega_{\mathrm{OH}} / 2 \mathrm{~cm}^{-1}$. The uncertainties represent one standard deviation. The angular momentum distributions are plotted in (b). Here each point represents all trajectories that have $\mathrm{OH}$ angular momentum between $j_{\mathrm{OH}^{-}}-1$ and $j_{\mathrm{OH}}+1$. All plots are normalized so that the sum of the relative cross sections is unity. 


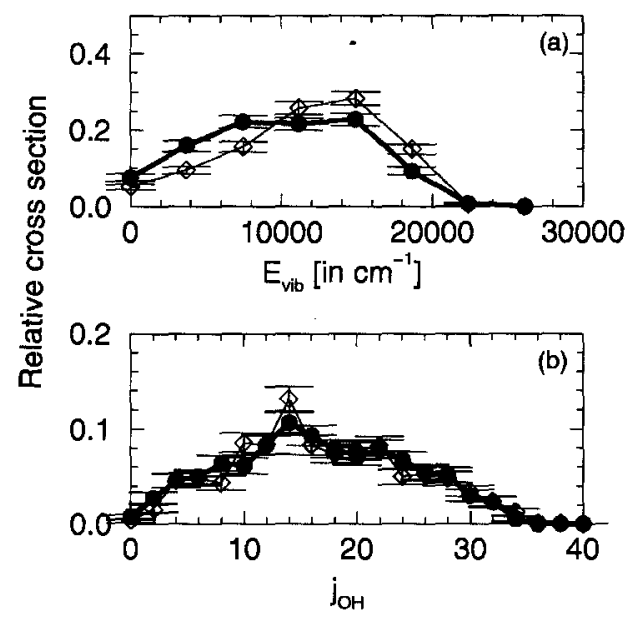

FIG. 7. Same as Fig. 4 for the $\mathrm{O}\left({ }^{1} D\right)+\mathrm{HCl}$ reaction.

between the angular momentum distributions of the $\mathrm{OH}$ formed from $\mathrm{O}+\mathrm{Ar}-\mathrm{HCl}$ and $\mathrm{O}+\mathrm{HCl}$ collisions.

\section{The Ar atom as a "cooling element"}

Comparing the dynamics of $O\left({ }^{3} P\right)$ and $O\left({ }^{1} D\right)$ collisions with $\mathrm{HCl}$ and $\mathrm{Ar} \cdot \cdot \mathrm{HCl}$ there are several significant differences. First, for the $\left.\mathrm{O}^{3} \mathrm{P}\right)+\mathrm{Ar} \cdot \mathrm{HCl}$ collisions, the lifetime of the collision complex is short compared to the lifetime of the $\mathrm{Ar} \cdots \mathrm{OH}$ complex. This difference is manifested in the observation that the rotational and vibrational energies of the $\mathrm{OH}$ products are lower for reactions of $\mathrm{Ar} \cdots \mathrm{HCl}$ than they are for the $\mathrm{HCl}$ reactions. In contrast, in $\mathrm{O}\left({ }^{1} D\right)+\mathrm{Ar} \cdots \mathrm{HCl}$ collisions, the $\mathrm{HOCl}$ collision complex survives for as long as several picoseconds. Due to the large energy difference between the reactants and the products, the argon atom leaves promptly thereby having a minor effect on the energy distributions of the $\mathrm{OH}$ products. In this case the $\mathrm{OH}$ product state distribution will be determined by the lifetime of the $\mathrm{HOCl}$ complex.

These results point to the conditions under which the complexing atom or molecule can act as an effective "cooling element." If the collision complex lifetime is short relative the time required for the van der Waals complex to fall apart, then rotational cooling takes place. However, if the collision complex is long lived relative to the lifetime of the van der Waals complex, then the product state energy distribution will be similar to that observed for the corresponding reaction of uncomplexed species.

To test the above hypothesis we look at the second product channel that is populated by $1 \mathrm{eV}$ collisions of $\mathrm{O}\left({ }^{1} D\right)$ with $\mathrm{HCl}$ : the $\mathrm{H}+\mathrm{OCl}$ products. To obtain improved statistics for this comparison, we ran these trajectories with a maximum impact parameter of $3.97 \AA$. This yields 139 and 171 reactive trajectories for the collisions of $\mathrm{O}\left({ }^{1} D\right)$ with $\mathrm{HCl}$ and $\mathrm{Ar} \cdot \cdot \mathrm{HCl}$, respectively.

In Fig. 8 we compare the lifetimes of the collision and van der Waals complexes, as we did for the $\mathrm{OH}$ channel in Fig. 6. Here we define the $\mathrm{HOCl}$ complex to dissociate when the $\mathrm{OH}$ and $\mathrm{HCl}$ distances both exceed $2.17 \AA$, and the van der Waals complex is dissociated when $r_{\mathrm{Ar} \cdots \mathrm{oCl}}$ becomes larger than $5.29 \AA$. In this case, the $\mathrm{HOCl}$ lifetimes, plotted

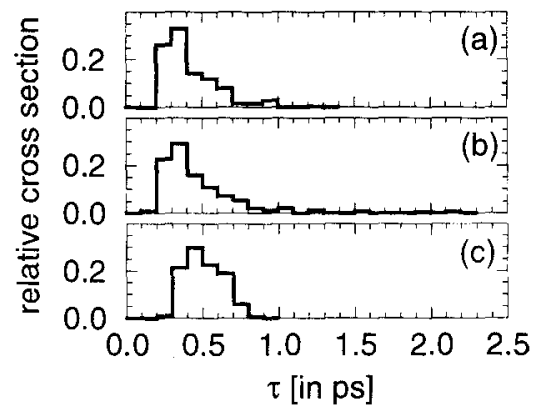

FIG. 8. Same as Fig. 3 for the $\mathrm{OCl}$ product channel of the $\mathrm{O}\left({ }^{1} D\right)+\mathrm{HCl}$ reaction.

in Figs. 8(a) and 8(b), are similar, and the $\mathrm{Ar} \cdots \mathrm{OCl}$ complex has a longer lifetime, on average. In Fig. 9 we plot the OCl rotational and vibrational distributions and, as expected by our model, the distributions are colder for the $\mathrm{O}\left({ }^{1} D\right)+\mathrm{Ar} \cdots \mathrm{HCl}$ reactions than for the $\mathrm{O}\left({ }^{1} D\right)+\mathrm{HCl}$.

\section{SUMMARY AND CONCLUSIONS}

To summarize, we have found that for the reaction of $\mathrm{O}\left({ }^{1} D\right)$ with $\mathrm{HCl}$ the rotational distribution of the $\mathrm{OH}$ products is insensitive to complex formation. This result is in stark contrast to previous work on $\mathrm{O}\left({ }^{3} P\right)$ collisions with hydrocarbon molecules complexed with rare gas atoms, where the product state distribution of the $\mathrm{OH}$ was significantly cooler than in the reactions with $\mathrm{HCl}$ monomer. ${ }^{40} \mathrm{We}$ have rationalized the above findings by running classical simulations of the atomic oxygen $+\mathrm{HCl}$ reactions for $\mathrm{O}\left({ }^{1} D\right)$ and $\mathrm{O}\left({ }^{3} P\right)$ and compare the $\mathrm{OH}$ rotational distributions to those obtained when $\mathrm{HCl}$ is in a van der Waals complex. Our results are consistent with the experimental findings. By studying the trajectories, we find that the effectiveness of argon as a "cooling element" is closely related to the life-

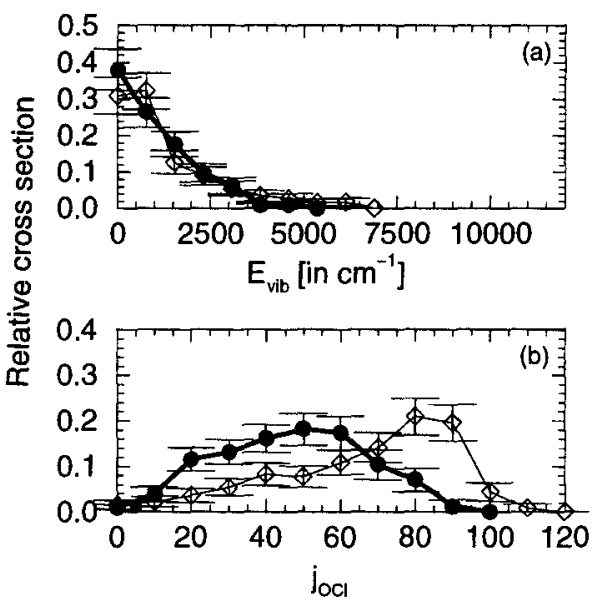

FIG. 9. Internal energy distributions for $\mathrm{OCl}$ formed from reactions of $\mathrm{O}\left({ }^{1} D\right)$ with $\mathrm{HCl}$ (thin line) and $\mathrm{Ar}-\mathrm{HCl}$ (broad line). In (a), the vibrational energy distributions of the $\mathrm{OCl}$ products are plotted. Each point represents results that have vibrational energies between $E_{\mathrm{vib}}-\omega_{\mathrm{OC}} / 2 \mathrm{~cm}^{-1}$ and $E_{\mathrm{vib}}+\omega_{\mathrm{OCl}} / 2 \mathrm{~cm}^{-1}$. The uncertainties represent one standard deviation. The angular momentum distributions are plotted in (b). Here each point represents all trajectories that have $\mathrm{OCl}$ angular momentum between $j_{\mathrm{OCl}}-5$ and $j_{\mathrm{OCl}}+5$. All plots are normalized so that the sum of the relative cross sections is unity. 
times of the collision and van der Waals complexes. This is further verified by comparing the $\mathrm{OCl}$ product state distributions for $\mathrm{O}\left({ }^{1} D\right)$ collisions with $\mathrm{HCl}$ and $\mathrm{Ar} \cdots \mathrm{HCl}$. Here the lifetime of the complexes of $\mathrm{Ar}$ with $\mathrm{OCl}$ are longer lived than the $\mathrm{OHCl}$ complex and the corresponding $\mathrm{OCl}$ angular momentum and vibrational energy distributions are colder.

\section{ACKNOWLEDGMENTS}

M.W.L. was supported by a summer fellowship through the NSF-REU program at Ohio State. A.B.M. gratefully acknowledges support from the donors to the Petroleum Research Fund administered by the American Chemical Society, the National Science Foundation (US) CAREER program under Grant No. CHE-9732998, and the Ohio State University board of regents for the work performed at Ohio State. A.B.M. and R.N. also acknowledge support from the US-Israel Binational science foundation.

${ }^{1}$ W. H. Miller, Annu. Rev. Phys. Chem. 41, 245 (1990).

${ }^{2}$ D. E. Manolopoulos, K. Stark, H. J. Werner, D. W. Arnold, and D. N. Neumark, Science 262, 1852 (1993).

${ }^{3}$ G. C. Schatz, J. Phys. Chem. 100, 12839 (1996).

${ }^{4}$ S. K. Shin, Y. Chen, S. Nikolaisen, S. W. Sharpe, R. A. Beaudet, and C. Wittig, Adv. Photochem. 16, 249 (1991).

${ }^{5}$ S. P. Sapers, V. Vaida, and R. Naaman, J. Chem. Phys. 88, 3638 (1988).

${ }^{6}$ V. Vaida, D. J. Donaldson, S. P. Sapers, R. Naaman, and M. S. Child, J. Phys. Chem. 93, 513 (1989).

${ }^{7}$ Y. B. Fan and D. J. Donaldson, J. Chem. Phys. 97, 189 (1992).

${ }^{8}$ C. Jouvet, M. Boivinear, M. C. Duval, and B. Soep, J. Phys. Chem. 91, 5416 (1987)

${ }^{9}$ W. H. Breckenridge, Acc. Chem. Res. 22, 21 (1989).

${ }^{10}$ A. B. McCoy, Y. Hurwitz, and R. B. Gerber, J. Phys. Chem. 97, 12516 (1993).

${ }^{11}$ K. M. Christoffel and J. M. Bowman, J. Chem. Phys. 104, 8348 (1996).

${ }^{12}$ R. Naaman, Adv. Chem. Phys. 70, 181 (1988).

${ }^{13}$ D. R. Worsnop, S. J. Buelow, and D. R. Herschbach, J. Phys. Chem. 85, 3024 (1981)

${ }^{14}$ O. Cheshnovsky and S. Leutwyler, J. Chem. Phys. 88, 4127 (1988),

${ }^{15}$ J. Steadman and J. A. Syage, J. Chem. Phys. 92, 4630 (1990).

${ }^{16}$ E. R. Bernstein, J. Phys. Chem. 96, 10105 (1992).
${ }^{17}$ Y. Hurwitz, P. Stern, R. Naaman, and A. B. McCoy, J. Chem. Phys. 106, 2627 (1997).

${ }^{18}$ J. M. C. Marques, W. Wang, A. A. C. C. Pais, and A. J. C. Varandas, J. Phys. Chem. 100, 17513 (1996).

${ }^{19}$ Y. Hurwitz, Y. Rudich, R. Naaman, and R. B. Gerber, J. Chem. Phys. 98, 2941 (1993).

${ }^{20}$ W. H. Thompson and W. H. Miller, J. Chem. Phys. 106, 142 (1997).

${ }^{21}$ M. J. Davis, H. Koizumi, G. C. Schatz, S. E. Bradforth, and D. M. Neumark, J. Chem. Phys. 101, 4708 (1994).

${ }^{22}$ R. J. Cicerone, Science 237, 35 (1987).

${ }^{23}$ M. L. Hernandez, C. Redondo, A. Lagana, G. Ochoa de Aspuru, G. M. Rosi, and A. Sgamellotti, J: Chem. Phys. 105, 2710 (1996), and references cited therein.

${ }^{24}$ B. Ramachandran, J. Senekowitsch, and R. E. Wyatt, Chem. Phys. Lett. 270, 387 (1997).

${ }^{25}$ N. Balucani, L. Beneventi, P. Casavecchia, and G. G. Volpi, Chem. Phys. Lett. 180, 34 (1991)

${ }^{26}$ A. I. Chichinin, J. Chem. Phys. 106, 1057 (1997).

${ }^{27}$ Y. Naitoh, Y. Fujimura, O. Kajimoto, and K. Honma, Chem. Phys. Lett. 190, 135 (1992).

${ }^{28}$ Y. Naitoh, Y. Fujimura, K. Honma, and O. Kajimoto, Chem. Phys. Lett. 205, 423 (1993).

${ }^{29}$ Y. Hurwitz, Y. Rudich, and R. Naaman, Isr. J. Chem. 34, 59 (1994).

${ }^{30}$ H. R. Mayne, in Dynamics of Molecules and Chemical Reactions, edited by R. E. Wyatt and J. Z. H. Zhang (Dekker, New York, 1996), pp. 589616.

${ }^{31}$ L. M. Ruff and D. L. Thompson, in Theory of Chemical Reaction Dynamics, edited by M. Baer (Chemical Rubber, Boca Raton, FL, 1985), Vol. 3.

${ }^{32}$ H. Koizumi, G. C. Schatz, and M. S. Gordon, J. Chem. Phys. 95, 6421 (1991).

${ }^{33}$ R. Schinke, J. Chem. Phys. 80, 5510 (1984).

${ }^{34}$ J. M. Hutson, J. Chem. Phys. 89, 4550 (1988).

${ }^{35}$ Z. Ma, K. Liu, L. B. Harding, M. Komotos, and G. C. Schatz, J. Chem. Phys. 100, 8026 (1994).

${ }^{36}$ M. I. Lester, W. H. Green, C. Chakravarty, and D. C. Clary, in Molecular Dynamics and Spectroscopy by SEP, edited by R. Field and H. Dai (World Scientific, Singapore, 1995).

${ }^{37}$ R. W. Bickes, Jr., B. Lantzsch, J. P. Toennies, and K. Walaschweski, Faraday Discuss. Chem. Soc. 55, 167 (1973).

${ }^{38}$ V. Aquilanti, R. Candori, D. Cappelletti, V. Lorent, E. Luzzatti, and F. Pirani (unpublished)

${ }^{39}$ A. D. Esposti and H. Werner, J. Chem. Phys. 93, 3351 (1990).

${ }^{40}$ Y. Rudich, Y. Hurwitz, G. J. Frost, V. Vaida, and R. Naaman, J. Chem. Phys. 99, 4500 (1993). 